Homepage: http://epubs.icar.org.in/ejournal/index.php/JWR

\title{
Physiological differences at different growth stages of wheat and their effect on yield and yield attributing traits
}

\author{
Chandra Nath Mishra ${ }^{1}$, Vinod Tiwari ${ }^{1}$, Amit Kumar ${ }^{2}$, Satish Kumar ${ }^{*}$, Gyanendra Singh ${ }^{1}$ and \\ Gyanendra Pratap Singh ${ }^{1}$ \\ ${ }^{1}$ ICAR-Indian Institute of Wheat and Barley Research, Karnal - 132001 (India) \\ ${ }^{2}$ ICAR-Research Complex for NEH Region, Umiam, Meghalaya, India
}

\section{Article history}

Received: 16 Nov., 2020

Revised : 11 Dec., 2020

Accepted: 26, Dec., 2020

\section{Citation}

Mishra CN, V Tiwari, A Kumar, S Kumar, G Singh and GP Singh. 2020. Physiological diffrences at different growth stages of wheat and their effect on yield and yield attributing traits. Journal of Cereal Research 12(3): 317-326. http://doi.org/10.25174/25822675/2020/107292

\section{*Corresponding author}

Email: kumarsatish227@gmail.com

(C) Society for Advancement of Wheat and Barley Research

\begin{abstract}
India being the second largest wheat producer in the world provides $13 \%$ of global wheat supply. Traditional breeding approaches are limited by the low genetic variability, complexity of stress tolerance traits and yield components and the lack of efficient selection techniques under stress conditions. Although the physiological tolerance indices are not directly related to yield but their use might prove increasingly useful. Integration of physiological traits complimented with efficient breeding methodologies will drive the present research to the required wheat yields. A set of twelve wheat lines were used to study the effect of different physiological parameters on the overall yield and its component traits. Progressive increase in NDVI values was noticed during the vegetative phase and a definite decline in values was observed during milk development to ripening stages in the genotypes. In high yielding genotypes a sharp decline of NDVI values was observed from anthesis to milk development stage. This set of genotypes generally showed a slower increase in NDVI values from seedling growth stage to inflorescence emergence stage and faster decline from inflorescence stage to ripening stage. The grain filling occurs in high temperatures and genotypes showing faster utilization of green matter showed higher yield.
\end{abstract}

Keywords: Wheat, NDVI, CT, Grain Yield, Physiology, Mauchly's sphericity test

\section{Introduction}

India being the second largest wheat producer in the world provides 13\% of global wheat supply (FAO, 2018). Traditional breeding approaches are limited by the low genetic variability, complexity of stress tolerance traits and yield components and the lack of efficient selection techniques under stress conditions. Although the physiological tolerance indices (osmotic adjustment, membrane stability, relative water content etc.) are not directly related to yield but their use might prove increasingly useful. Integration of these physiological traits complimented with efficient breeding methodologies will drive the present research to the required yield heights. Several researches identified physiological traits having direct correlation with improved genetic yield gains in wheat. Selection techniques based on physiological parameters are now being evaluated for their role as supplementary tool in wheat breeding at CIMMYT (Reynold et al., 2001). Identification of dependable screening methods and efficient selection criteria with physiological input remains a major challenge in traditional breeding programme. Physiological-traitbased breeding is also good strategy and has merit over breeding for yield per se because it increases the probability of crosses resulting in additive gene action, although considerable investment in germplasm characterization is prerequisite. 
The use of spectral indices as a selection tool in plant breeding could improve genetic gains for different important traits (Babar et al., 2006). Most of these indices have been used for assessment in the last part of crop cycle usually in cereals after anthesis (Marti et al., 2007) and less information is available on the use of Normalized Difference Vegetative Index (NDVI) in relatively early stages. Use of spectral vegetation indices has also been advocated to predict crop status across a broad range of growth stages (Aparicio et al., 2002). Physiological parameters are being effectively used in wheat breeding (Reynold et al., 2007). According to the physiological considerations, survival is the main aim of plant during any stress, whereas from the agricultural point of view yield is the determining drought tolerance trait. In general, change in plant architecture, coleoptile elongation, growth inhibition, scorching of leaves and stems, leaf abscission and senescence are some characteristic symptoms of physiological injuries which have been observed under elevated temperatures and which consequently lead to reduced plant productivity (Tian et al., 2014). Better understanding of the variability available for physiological traits during different phenological stages would help in improving the efficiency of wheat breeding.

Repeated measures are consecutive data obtained over time from the same experimental units such as plants or animals (Littell et al., 1996) and the objectives are to examine and compare response trends over time. The comparisons of treatments can be at specific times, or averaged over time and it also can involve comparisons of times within a treatment (Littell et al., 1998). Repeated ANOVA is applied traditionally for statistical analysis of data including between-subject and within-subject factors and is used safely when sphericity assumption is provided (Eyduran and Akbas, 2010). The sphericity assumption is an assumption about the structure of the covariance matrix in a repeated measures design. It was observed that multivariate methods gave more reliable results than univariate methods (Tabachnick and Fidel, 2001; Gurbuz et al., 2003).

With the above views in consideration the present investigation was carried out to study the time response of the NDVI in a set of wheat genotypes to characterize expressed spatial variability as a function of physiological growth stages.

\section{Materials and methods}

The present experiment was carried out on nine advanced wheat lines and three check varieties viz., DBW88, WH1105 and HD2967. The parentage details of the tested lines are presented in table 1 . All the 12 treatments were grown in Randomized Complete Block Design with three replications during 2016-17 crop season at ICAR-Indian Institute of Wheat and Barley Research Karnal, India. Each plot consisted of 12 rows of 6 meters length spaced $20 \mathrm{~cm}$ apart. All the recommended agronomic practices were applied to raise the good crop.

\section{Observations recorded}

Agro-morphological traits: Data were recorded on all the treatments for agronomic traits viz., days to heading, plant height, flag leaf width, number of productive tillers per meter, spike length, grain yield and thousand grains weight.

Physiological traits: Data of leaf area index, canopy temperature (CT) and Normalized Difference Vegetative Index (NDVI) were carried out following standard trait dictionary of CIMMYT (Pask et al., 2012). NDVI was measured with the help of hand held Trimble GreenSeeker and was recorded at following eight growth stages:

NDVI 1 (seedling growth stage)

NDVI 2 (tillering stage)

NDVI 3 (stem elongation stage)

NDVI 4 (inflorescence emergence stage)

NDVI 5 (anthesis stage)

NDVI 6 (milk development stage)

NDVI 7 (soft dough stage)

NDVI 8 (ripening stage)

\section{Statistical analysis}

The range of dispersion for all the traits was analyzed in SAS 9.3 using Proc MEANS statement. The data of NDVI was observed at 8 intervals for each genotype. Repeated measure analysis was done using GLM procedure of SAS 9.3 using REPEATED statement. This approach basically bypassed the problems of covariance structure rather than addressing them directly. The REPEATED statement enabled users to obtain statistical tests for effects 
Table 1: Details of the plant materials used in the study

\begin{tabular}{lll}
\hline SN & Entry Name & Pedigree \\
\hline 1 & DBW 244 & WR1206/F81.513//Milan-1/3/PBW509 \\
2 & CA 47th IBWSN 808 & BLUEGIL-3/3/NG8675/CBRD//MILAN/4/PSN/BOW//MILAN/5/ \\
& & KIRITATI/2*TRCH \\
3 & DBW 235 & MELON//FILIN/MILAN/3/FILIN/4/TRCH/SRTU//KACHU \\
4 & DBW 224 & KACHU/6/YAR/AE.SQUARROSA (783)/4/GOV/AZ//MUS/3/SARA/5/MYNA/ \\
5 & DBW 166 & DANPHE/CHONTE \\
6 & DBW 140 & PFAU/MILAN/4/CROC_1/A.SQUARROSA(205)//KAUZ/3/2*ATILLA/3*BCN \\
7 & 31st SAWSN 3189 & PRL/2*PASTOR*2//FH6-1-7 \\
8 & CA 47th IBWSN 938 & SWSR22T.B./4/2*BABAX/LR42//BABAX*2/3/KURUKU/5/WBLL1*2/KURUKU \\
9 & LBP 2015-1 & HD2733/BH1146 \\
10 & DBW 88 (C) & KAUZ//ALTAR84/AOS/3/MILAN/KAUZ/4/HUITES \\
11 & WH 1105 (C) & MILAN/S87230//BABAX \\
12 & HD 2967 (C) & ALD/CUC//URES/HD2160M/HD2278 \\
\hline
\end{tabular}

Table 2: Variability and basic statistics observed in the set of genotypes

\begin{tabular}{|c|c|c|c|c|c|c|}
\hline S.N. & Variable & Range & Mean & $\operatorname{Std} \operatorname{Dev}(\mathrm{SD})$ & $\mathrm{CV}(\%)$ & Std Error(SE) \\
\hline \multicolumn{7}{|c|}{ Agronomic traits } \\
\hline 1 & Days to heading & $89.00-118$ & 101.78 & 7.35 & 7.22 & 1.23 \\
\hline 2 & Plant height $(\mathrm{cm})$ & $92.00-119.0$ & 103.50 & 5.88 & 5.68 & 0.98 \\
\hline 3 & Flag leaf width $(\mathrm{cm})$ & $1.70-3.10$ & 2.09 & 0.32 & 15.53 & 0.05 \\
\hline 4 & $\begin{array}{l}\text { Number of productive } \\
\text { tillers per meter }\end{array}$ & $75.00-128$ & 95.64 & 13.51 & 14.13 & 2.25 \\
\hline 5 & Spike length $(\mathrm{cm})$ & $7.40-12.80$ & 9.83 & 1.12 & 11.42 & 0.19 \\
\hline 6 & Yield (q/ha) & $25.02-55.98$ & 47.10 & 7.19 & 15.27 & 1.20 \\
\hline 7 & TGW (g) & $30.98-50.20$ & 38.89 & 5.49 & 14.12 & 0.92 \\
\hline \multicolumn{7}{|c|}{ Physiological traits } \\
\hline 1 & Leaf area index & $4.45-8.04$ & 5.79 & 0.83 & 14.33 & 0.14 \\
\hline 2 & CT at heading & $12.90-18.30$ & 15.48 & 1.42 & 9.20 & 0.24 \\
\hline 3 & CT at 15DAA & $15.60-26.10$ & 20.41 & 2.04 & 10.01 & 0.34 \\
\hline 4 & NDVI1 & $0.46-0.82$ & 0.64 & 0.09 & 14.00 & 0.01 \\
\hline 5 & NDVI2 & $0.59-0.85$ & 0.74 & 0.06 & 8.62 & 0.01 \\
\hline 6 & NDVI3 & $0.67-0.89$ & 0.79 & 0.05 & 5.95 & 0.01 \\
\hline 7 & NDVI4 & $0.81-88$ & 0.85 & 0.02 & 1.97 & 0.00 \\
\hline 8 & NDVI5 & $0.80-0.86$ & 0.83 & 0.02 & 2.01 & 0.00 \\
\hline 9 & NDVI6 & $0.71-0.81$ & 0.77 & 0.03 & 3.29 & 0.00 \\
\hline 10 & NDVI7 & $0.65-0.79$ & 0.73 & 0.04 & 4.90 & 0.01 \\
\hline 11 & NDVI8 & $0.55-0.77$ & 0.67 & 0.05 & 6.74 & 0.01 \\
\hline
\end{tabular}


involving time trends. Regressions were calculated using REG procedures of SAS 9.3 software (SAS Institute Inc., Cary, NC, USA).

\section{Results and discussion}

Variability for agro-morphological traits studied: Data presented in Table 2. indicates that there was ample amount of variability present in the genotypes tested. The days to heading ranged from 89 to 118 days after sowing with the mean value of 101.8 days. The coefficient of variation for the trait was $7.22 \%$. The average height of the genotypes was $103.5 \mathrm{~cm}$ and it varied from 92 to $119 \mathrm{~cm}$ (CV 5.68\%). The flag leaf width averaged at 2.09 $\mathrm{cm}$ and it ranged from 1.73 to $3.10 \mathrm{~cm}$ (CV 15.53\%). The number of productive tillers per meter ranged from 75 to 128 (CV 14.13\%) with mean value of 95.6. Spike length of the genotypes varied from 7.4 to $12.8 \mathrm{~cm}$ (CV 11.42\%) with mean value of $9.83 \mathrm{~cm}$. The grain yield of genotypes ranged from $25.02 \mathrm{q} /$ ha to $55.98 \mathrm{q} / \mathrm{ha}$ (CV 15.27\%) and average yield of genotypes was $47.10 \mathrm{q} / \mathrm{ha}$. The 1000 grains weight of the tested genotypes varied from 30.98 to $50.20 \mathrm{~g}$ (CV $14.12 \%)$ with mean value of $38.89 \mathrm{~g}$.

Variability for physiological traits studied:The leaf area index of the genotypes ranged from 4.45 to 8.04 (CV 14.3\%) with mean value of 5.79. The Canopy temperature at heading in genotypes varied from 12.9 to 18.30 (CV 9.20\%) with mean of 15.48 . The $\mathrm{CT}$ at $15 \mathrm{DAA}$ had ranged from 15.6 to $26.10(\mathrm{CV} 10.01 \%)$ with mean of 20.41 .

NDVI recorded during eight growth stages i.e. NDVI1 (seedling growth stage), NDVI 2 (tillering), NDVI3 (stem elongation), NDVI4 (Inflorescence emergence), NDVI 5 (anthesis), NDVI 6 (milk development), NDVI 7 (dough development) and NDVI 8 (ripening) showed significant variation. NDVI 1 ranged from 0.46 to 0.82 with average of 0.64 , NDVI 2 ranged from 0.59 to 0.85 with average of 0.74 , NDVI 3 ranged from 0.67 to 0.89 with average of 0.79 , NDVI 4 ranged from 0.81 to 0.88 with average of 0.85 , NDVI 5 ranged from 0.80 to 0.86 with average of 0.83 , NDVI 6 ranged from 0.71 to 0.81 with average of 0.77 , NDVI 7 ranged from 0.65 to 0.79 with average of 0.73 , and NDVI 8 ranged from 0.55 to 0.77 with average of 0.67 .

Progressive increase in NDVI values was noticed during the vegetative phase in both minimum and maximum values (Fig.1) and definite decline in these values was observed from NDVI 6 (milk development) to NDVI 8 (ripening stage). The coefficient of variation presented in table 2 shows that maximum variation for NDVI values was observed during seedling growth stage $(14.00 \%)$, as the genotypes progressed towards tillering stage, the $\mathrm{CV}$ reduced to $8.62 \%$, at stem elongation stage it was 5.95 , at inflorescence emergence it was minimum (1.97\%), there after again the variation started increasing and it was 2.01 at anthesis and $3.29 \%$ at milk development stage. At the time of dough development and ripening the coefficient of variation was observed as $4.90 \%$ and $6.74 \%$, respectively (Fig 1). The ability of NDVI readings to detect growth stage specific variability provides exciting prospect as past work has shown that early season NDVI readings have been highly correlated with total biomass and yield potential (Raun et al., 2005). It is important to note that peaks for spatial variability were observed at seedling stage indicates the genotypic differences for early vigour and during ripening stage was due to differences among genotypes for decomposition of chlorophyll during grain formation.

The NDVI values observed during the different growth stages in the experiment were subjected to the repeated measure analysis with the objective to understand the change in treatment mean over time and whether there is treatment by time interaction or not.

\section{Between Subject and Within Subject Effect}

In repeated measure analysis, two types of factors namely between subject and within subject factor (WSFs) were analyzed as it is quite important to distinguish between these two factors. Between subject factor levels are characterized by independent subjects and provide unrelated observations, whereas within subject factors (WSFs) has levels that represent repeated measurements observed on the same treatment and this repeatedly assessed subjects and give rise to correlated measurements across the levels of any WSFs (Thongbam et al., 2014). Between-subject effects, which is a case of univariate tests of hypotheses are presented in Table 3. The effect of genotypes tested in this experiment were found to be significant $(\mathrm{F}=3.66)$ as far as NDVI is concerned. Also within subject effects which include time parameter in addition to genotype and thus incorporates a new dimension of genotype $\mathrm{x}$ time interaction, were calculated. 


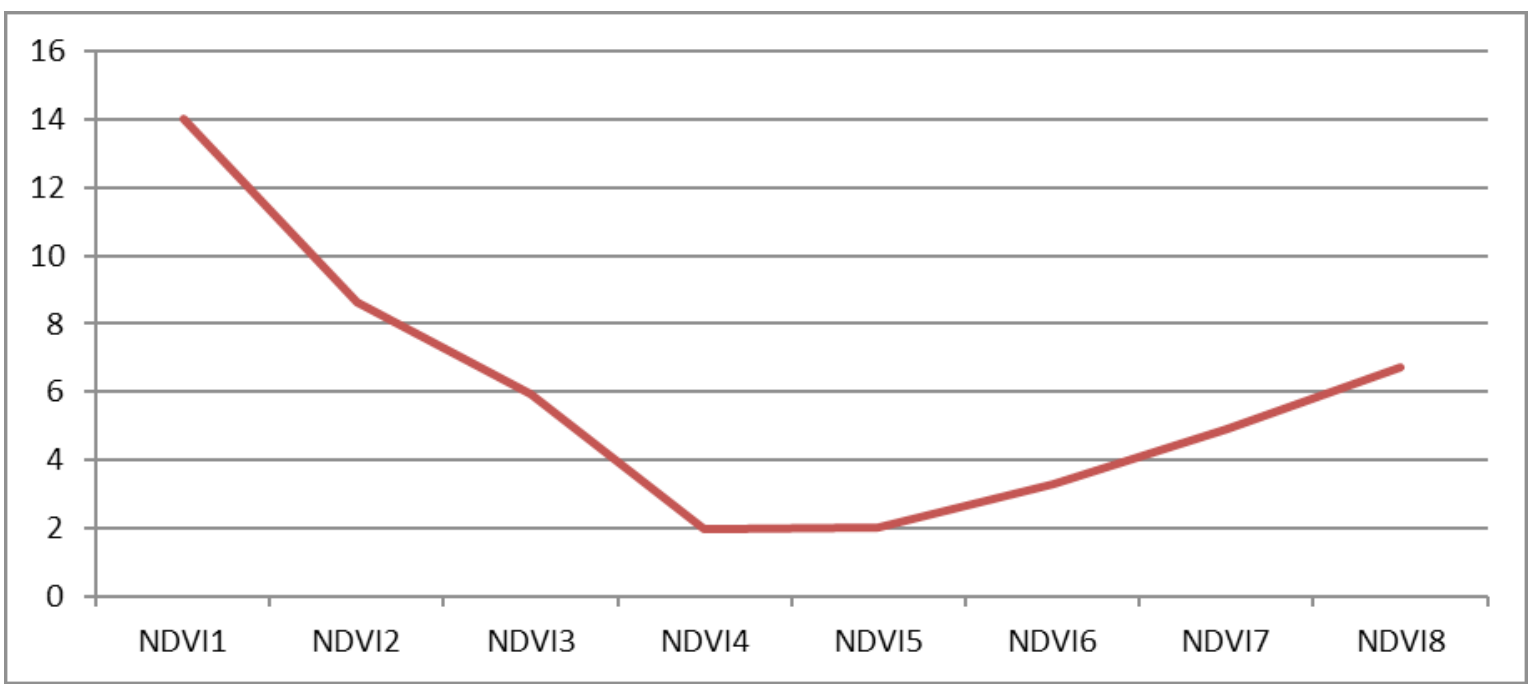

Fig 1: Relationship between the coefficient of variation $(\mathrm{CV})$ for normalized difference vegetative index (NDVI) sensor readings during different growth stages of wheat.

Table 3: Repeated measures analysis of variance for between subject effects (Univariate Tests of Hypotheses)

\begin{tabular}{llllll}
\hline Source & DF & Type III SS & Mean Square & F Value & Pr $>$ F \\
\hline Genotype & 11 & 0.09719 & 0.00884 & 3.66 & 0.0038 \\
Error & 24 & 0.05789 & 0.00241 & & \\
\hline
\end{tabular}

Both time as well as genotype $\mathrm{x}$ time effects were found to be significant revealing that significant difference (table 4) existed in the recordings of NDVI at different stages. This necessitates the selection of superior lines based on NDVI value, which itself is a reflection of high performance of genotypes. Greenhouse- Geisser (G-G) and Huynh-Feldt (H-F) Epsilon adjusted $\mathrm{F}$ test approaches are used when validity of spherity assumption was not provided. Repeated measure ANOVAs being prone to assumption of spherity that refers to the condition where variances of the differences between all combinations of related groups (levels) are equal, however where these are not equal violation of the spherity occurs (Table 5). These violations lead to the distortion of variance leading to inflated $\mathrm{F}$ ratio. In the present experiment, when these approaches were considered together, time effect was found to be highly significant $(<.0001)$ and interaction effect was significant $(<.05)$.

\section{Mauchly's sphericity test and epsilon adjustment values}

When Mauchly's Test of Sphericity is statistically significant $(\mathrm{p}<.05)$. alternative hypotheses are accepted stating variances of the differences are not equal and sphericity has been violated. This test helps in deciding the output; when output is univariate, there is more power to reject the null hypothesis otherwise multivariate approach should be followed. In the present experiment probability of Mauchly's test for spherciity assumption was significant $(\mathrm{P}<0.001)$. This means that multivariate approach should be chosen instead of univariate approach.

In Multivariate analysis of variance (MANOVA), the main concern is the examination of mean differences when two or more dependent variables are considered simultaneously. However, when the variables are not dependent there is probability of potential interaction which leads to inflation in the error, in such situation MANOVA is most appropriate test. Results of Multivariate analysis of variance are presented in table 6 . If the values of Wilks'Lambda is small (close to 0) null hypothesis is rejected. Similarly, if the values of Pillai trace, HotellingLawley Trace, Roy's Greatest Root statistics is large the null hypothesis is rejected. As observed from the table, Wilk's lambda value is close to zero and the value for Pillai trace, Hotelling-Lawley Trace, Roy's Greatest Root statistics is large leading to rejection of null hypothesis on time effect, indicating that NDVI values varied significantly over time. The same is also reflected in terms 


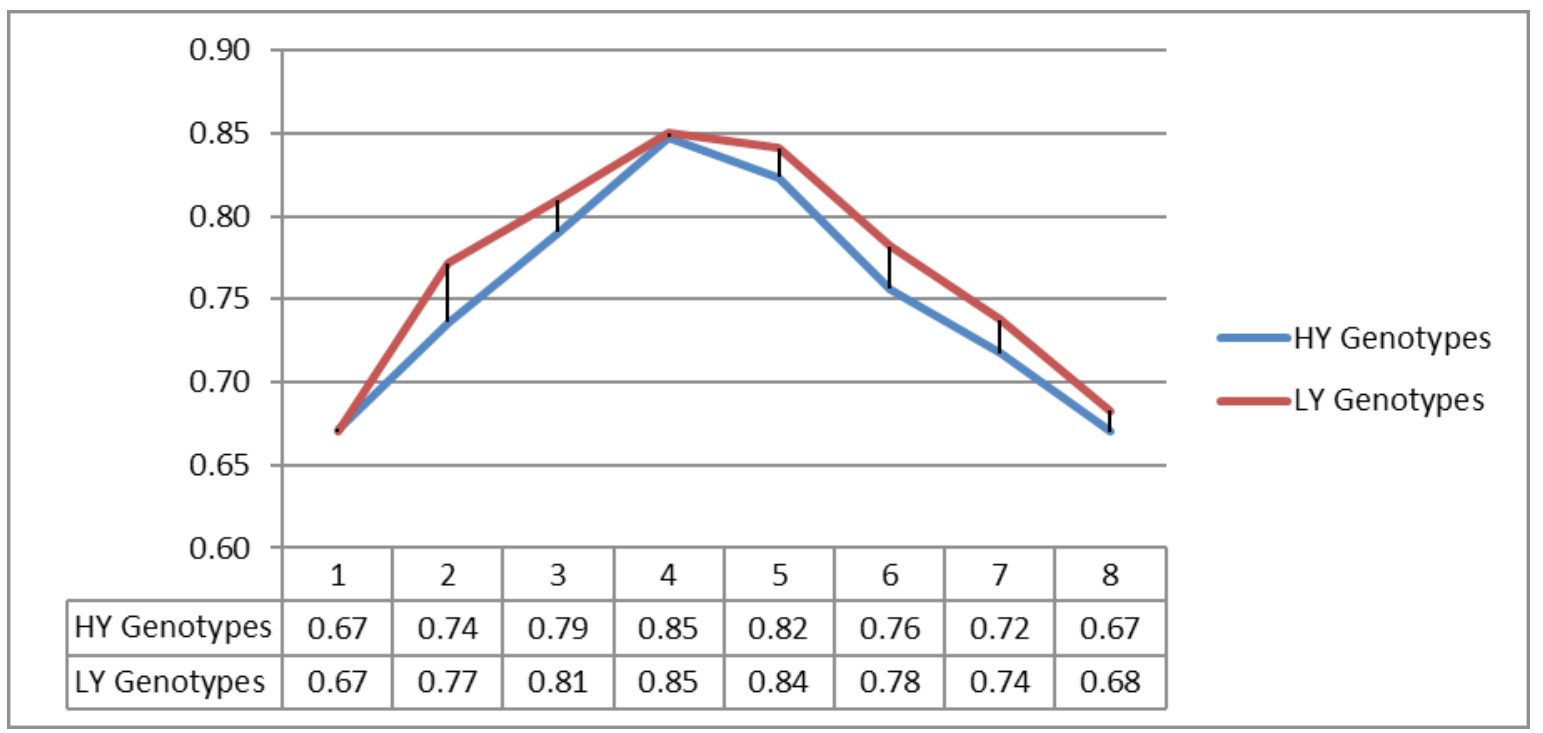

Fig 2: NDVI Pattern in high yielding and low yielding genotypes in different growth stages

Table 4. Repeated measures analysis of variance for within subject effects (Univariate Tests of Hypotheses)

\begin{tabular}{llllllll}
\hline Source & DF & Type III SS & Mean square & F Value & Pr $>$ F & Adj Pr $>$ F \\
\hline & & & & & & G - G & H-F-L \\
\cline { 3 - 6 } Time & 7 & 1.31356 & 0.18765 & 122.81 & $<.0001$ & $<.0001$ & $<.0001$ \\
Time*genotype & 77 & 0.24864 & 0.00323 & 2.11 & $<.0001$ & 0.0153 & 0.0121 \\
Error(Time) & 168 & 0.25671 & 0.00153 & & & & \\
\hline
\end{tabular}

Table 5. Sphericity Test results

\begin{tabular}{lllll}
\hline Mauchly's variables & DF & Criterion & Chi-Square & Pr $>$ ChiSq \\
Transformed variates & 27 & 0.00028 & 175.658 & $<.0001$ \\
Orthogonal components & 27 & 0.00028 & 175.658 & $<.0001$ \\
\hline
\end{tabular}

Table 6. MANOVA Test Criteria and Exact F Statistics for the hypothesis

\begin{tabular}{|c|c|c|c|c|c|c|}
\hline & Statistic & Value & F Value & Num DF & Den DF & $\operatorname{Pr}>F$ \\
\hline \multirow{4}{*}{$\begin{array}{l}\text { Hypothesis of no } \\
\text { Time Effect }\end{array}$} & Wilks' Lambda & 0.00642 & 398.06 & 7 & 18 & $<.0001$ \\
\hline & Pillai's Trace & 0.99358 & 398.06 & 7 & 18 & $<.0001$ \\
\hline & Hotelling-Lawley Trace & 154.799 & 398.06 & 7 & 18 & $<.0001$ \\
\hline & Roy's Greatest Root & 154.799 & 398.06 & 7 & 18 & $<.0001$ \\
\hline \multirow{5}{*}{$\begin{array}{l}\text { Hypothesis of no } \\
\text { Time* genotype } \\
\text { Effect }\end{array}$} & Wilks' Lambda & 0.00623 & 2 & 77 & 115.31 & 0.0004 \\
\hline & Pillai's Trace & 2.87528 & 1.52 & 77 & 168 & 0.0131 \\
\hline & Hotelling-Lawley Trace & 12.426 & 2.68 & 77 & 53.091 & 0.0001 \\
\hline & Roy's Greatest Root & 7.2933 & 15.91 & 11 & 24 & $<.0001$ \\
\hline & \multicolumn{4}{|c|}{ Greenhouse-Geisser Epsilon 0.2862, Huynh-Feldt-Lecoutre Epsilon } & 0.3122 & \\
\hline
\end{tabular}


Table 7. Regression between yield and other attributes for wheat genotypes

\begin{tabular}{|c|c|c|c|c|c|}
\hline Variable & $\mathrm{DF}$ & Parameter Estimate & Standard Error & $\mathrm{t}$ Value & $\operatorname{Pr}>|t|$ \\
\hline Intercept & 1 & 118.338 & 83.3249 & 1.42 & 0.1726 \\
\hline Leaf area index & 1 & -0.5767 & 1.69634 & -0.34 & 0.7378 \\
\hline CT heading & 1 & -0.0828 & 0.93759 & -0.09 & 0.9306 \\
\hline CT 15DAA & 1 & -2.4176 & 0.80167 & -3.02 & 0.0074 \\
\hline Tiller number & 1 & 0.22341 & 0.0985 & 2.27 & 0.0359 \\
\hline Flag leaf width & 1 & 6.12944 & 4.70382 & 1.3 & 0.209 \\
\hline Height & 1 & -0.548 & 0.32358 & -1.69 & 0.1076 \\
\hline DTH & 1 & 0.94612 & 0.52796 & 1.79 & 0.09 \\
\hline Spike length & 1 & -2.4636 & 1.34722 & -1.83 & 0.0841 \\
\hline TGW & 1 & 1.07336 & 0.3915 & 2.74 & 0.0134 \\
\hline NDVI1 & 1 & -39.48 & 25.9127 & -1.52 & 0.145 \\
\hline NDVI2 & 1 & 25.4027 & 34.0923 & 0.75 & 0.4658 \\
\hline NDVI3 & 1 & -41.669 & 39.1211 & -1.07 & 0.3009 \\
\hline NDVI4 & 1 & 99.1366 & 98.9728 & 1 & 0.3298 \\
\hline NDVI5 & 1 & -109.94 & 101.523 & -1.08 & 0.2931 \\
\hline NDVI6 & 1 & -81.672 & 98.8749 & -0.83 & 0.4196 \\
\hline NDVI7 & 1 & 44.4376 & 74.4953 & 0.6 & 0.5583 \\
\hline NDVI8 & 1 & -46.141 & 72.2419 & -0.64 & 0.5311 \\
\hline
\end{tabular}

of the probability of $\mathrm{F}$ value. Thus significant effect of time, and time and genotype interaction was observed in the present experiment. Significant effect of time and genotype interaction shows that the NDVI values varied significantly among different genotypes and also with time. The stage specific variation for NDVI values among different genotypes would provide ample opportunity for selection to be practiced.

In the present study, genotypic variation existed for NDVI at each of the eight growth stages used in this study. Stress may occur any growth stage of plants and therefore screening against a particular stress is understood to be got done in presence of the stress (Hazratkulova et al., 2012).

NDVI Pattern in high yielding and low yielding genotypes in different growth stages:

The mean NDVI values obtained in high yielding genotypes 2nd DBW235, WH1105(C), 2nd DBW224, and CA47th IBWSN 808 and low yielding genotypes DBW140, 31 SAWSN 3189, HD2967 and LBP2015-1 were subjected to graphical analysis presented in Fig 2 . The
NDVI values were highest and similar at the inflorescence emergence. Comparable values of NDVI in high yielding and low yielding genotypes at booting and flowering stage was also reported in crops (Thongbam et al., 2014). High NDVI values were noticed in low yielding genotypes at all the rest of stages. In high yielding genotypes sharp decline of NDVI values was observed from anthesis to milk development stage. High-yielding genotypes generally showed a slower increase in NDVI values from seedling growth stage to inflorescence emergence stage and faster decline from inflorescence stage to ripening stage. In the present environment, the grain filling occurs in high temperatures and genotypes showing faster utilization of green matter showed higher yield.

\section{Correlation among various traits}

Correlation and regression analysis (Table 7 and 8) on the set of genotypes revealed that there existed some significant correlations between the physiological traits studied and yield as well as days to heading (Morgounov et al., 2014). The NDVI recorded at later stages, particularly NDVI 6, 


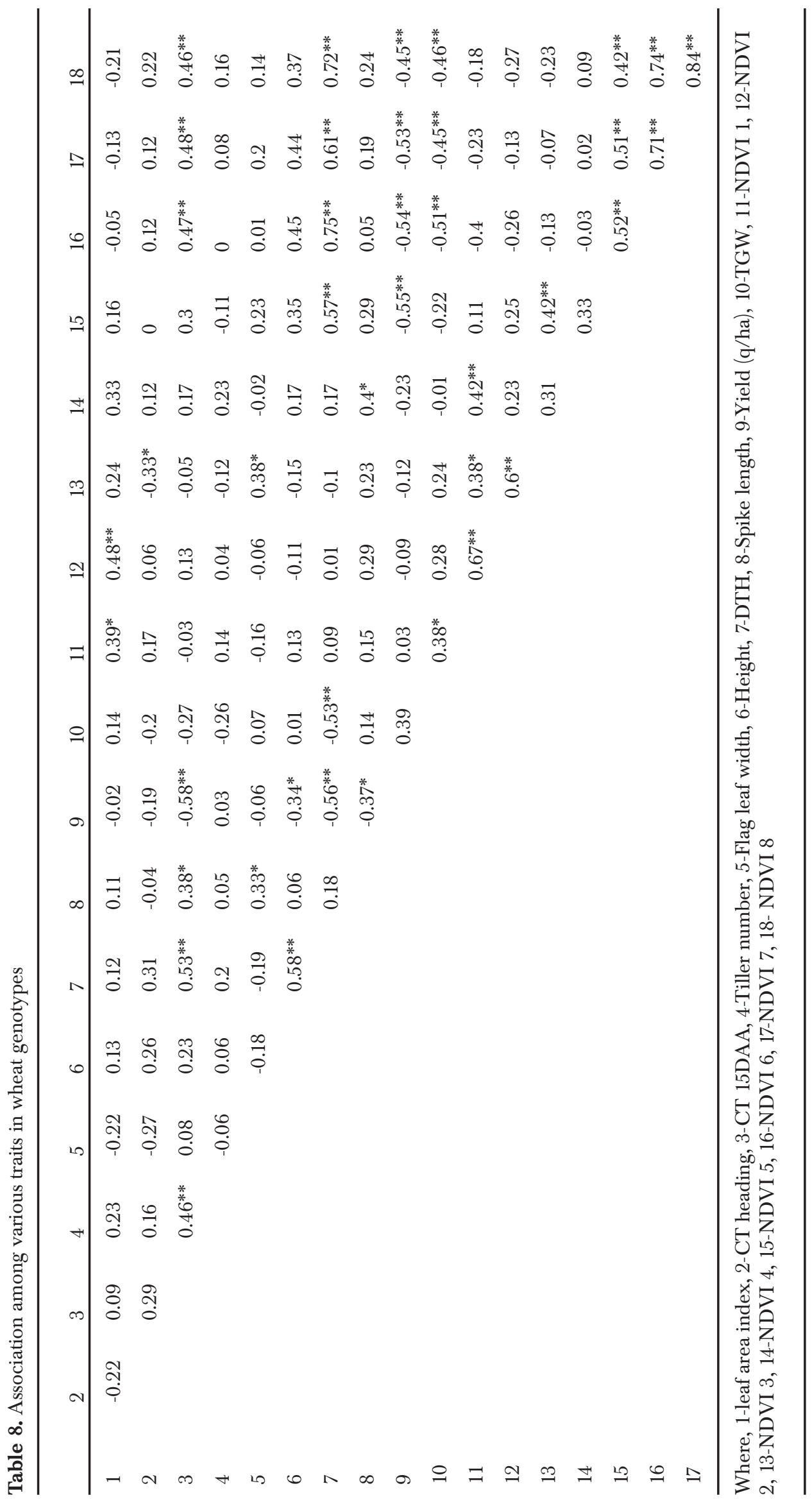


NDVI 7 and NDVI 8 showed highly significant correlation with days to heading, overall yield and thousand grains weight trait. In the present environment, the grain filling occurs in high temperatures and genotypes showing faster utilization of green matter showed higher yield. However, this may be a very small set of genotypes to infer any correlation, the results do cohere with the overall outcome of the study. The findings of present investigation have implications for wheat improvement programmes for

\section{References}

1. Aparicio N, D Villegas, JL Araus, J Casadesús and C Royo. 2002. Relationship between growth traits and spectral vegetation indices in durum wheat. Crop Science 42: 1547-1555.

2. Babar MA, MP Reynolds, M vanGinkel, AR Klatt, WR Raun and ML Stone. 2006. Spectral reflectance to estimate genetic variation for in-season biomass, leaf chlorophyll, and canopy temperature in wheat. Crop Science 46: 1046-1057.

3. Eyduran E and Y Akbas. 2010. Comparison of different covariance structure used for experimental design with repeated measurement. Journal of Animal and Plant Science 20: 44-51.

4. FAO (n.d.a) FAO, Food and Agriculture Organisation. URL: http://faostat3.fao.org/browse/Q/QC/E

5. Gurbuz F, E Bappýnar, H Çamdeviren and S Keskin. 2003. Analyzing experimental designs with repeated measurement. Publishing No. 130, Yuzuncu Yil University, Van.

6. Hazratkulova S, RC Sharma, A Safar, I Sarvar, T Yuldashev, Z Ziyaev, Z Khalikulov, Z Ziyadullaev and J Turok. 2012. Analysis of genotypic variation for normalized difference vegetation index and its relationship with grain yield in winter wheat under terminal heat stress. Plant Breeding 131: 716-721.

7. Littell RC, PR Henry and CB Ammerman. 1998. Statistical analysis of repeated measures data using SAS procedures. Journal of Animal Science 76: 1216-1231.

8. Littell RC, GA Milliken, WW Stroup and RD Wolfinger. 1996. SAS System for Mixed Models, developing high-yielding wheat varieties. The optimal stages for measuring NDVI vary depending on the germplasm and environment and little attention is paid by the different breeding programmes for field observations as little visual variation is present between genotypes, but our findings suggest that NDVI measurement at different stages would help in more precise selection of genotypes as there exists significant variation among high and low yielding genotypes at different growth stages.

SAS Institute Inc (Data Set 6.4). Cary, NC: http:// support.sas.com/

9. Marti J, J Bort, G Slafer and J Araus. 2007. Can wheat yield be assessed by early measurements of Normalized Difference Vegetation Index?. Annals of Applied Biology 150: 253-257.

10. Morgounov A, N Gummadov, S Belen, Y Kaya, M Keser and J Mursalova. 2014. Association of digital photo parameters and NDVI with winter wheat grain yield in variable environments. Turkish Journal of Agriculture and Forestry 38: 624-632.

11. Pask AJD, J Pietragalla, DM Mullan and MP Reynolds. 2012. Physiological breeding II: A field guide to wheat phenotyping. Mexico, DF: CIMMYT.

12. Raun WR, JB Solie, KL Martin, KW Freeman, ML Stone, GV Johnson and RW Mullen. 2005. Growth Stage, Development, and Spatial Variability in Corn Evaluated Using Optical Sensor Readings. Journal of Plant Nutrition 28: 173-182.

13. Reynolds M, F Dreccer and R Trethowan. 2007. Drought-adaptive traits derived from wheat wild relatives and landraces. Journal of Experimental Botany 58: $177-186$.

14. Reynolds MP, S Nagarajan, MA Razzaque and OAA Ageeb. 2001. Heat tolerance. In: Reynolds MP, Ortiz-Monasterio JI, McNab A (eds) Application of Physiology in Wheat Breeding. Mexico, D.F.: CIMMYT, pp 124-135.

15. Tabachnick BG and LS Fidel. 2001. Using Multivariate Statistics. Allyn and Bacon, USA. 
16. Thongbam PD, A Kumar, KKL Nonglait and A Pandey. 2014. Effect of total protein, total phenol, polyphenoloxidase, and peroxidase activity in rice (Oryza sativa) genotypes against Magnaporthe grisea. Indian Journal of Agricultural Sciences 84: 198-204.
17. Tian Y, C Zheng, J Chen, C Chen, A Deng, Z Song, B Zhang and W Zhang. 2014. Climatic warming increases winter wheat yield but reduces grain nitrogen concentration in East China. PlosOne 9(4) e95108. 